\title{
Study on a Novel Gelled Foam for Conformance Control in High Temperature and High Salinity Reservoirs
}

\author{
Tong Li ${ }^{1,+}$, Jichao Fang ${ }^{2,+}\left(\mathbb{D}\right.$, Baolei Jiao ${ }^{3}$, Long $\mathrm{He}^{3}$, Caili Dai ${ }^{2, *}$ and Qing You ${ }^{1, *(1 D}$ \\ 1 School of Energy Resources, China University of Geosciences, Beijing 100083, China; flitong@163.com \\ 2 State Key Laboratory of Heavy Oil Processing, China University of Petroleum, Qingdao 266580, China; \\ fjc805@163.com \\ 3 SINOPEC Northwest Branch Company Technology Research Institute of Petroleum Engineering, \\ Urumqi 830011, China; jbl.xbsj@sinopec.com (B.J.); paladinglong@163.com (L.H.) \\ * Correspondence: daicl@upc.edu.cn (C.D.); youqing@cugb.edu.cn (Q.Y.); Tel.: +86-532-8698-1183 (C.D.); \\ +86-010-8232-2754 (Q.Y.) \\ + These authors contributed equally to this work.
}

Received: 21 April 2018; Accepted: 22 May 2018; Published: 28 May 2018

\begin{abstract}
A novel gelled foam for conformance control was investigated for its ability to enhance oil recovery (EOR) in high temperature and high salinity reservoirs. The formulation optimization, foaming performance, and core flooding performance of the gelled foam were systematically evaluated under harsh reservoir conditions. The gelled foam formulation was optimized with $0.4 \%$ polymer (hydrolyzed polyacrylamide; HPAM), $0.06 \%$ cross-linker (phenolic) and $0.2 \%$ foaming agent (sulphobetaine; SB). The addition of the gel improved the stability of the foam system by 3.8 times that of traditional foam. A stabilization mechanism in the gelled foam was proposed to describe the stabilization process of the foam film. The uniformly distributed three-dimensional network structure of the gel provided a thick protective layer for the foam system that maintained the stability of the foam and improved the strength and thickness of the liquid film. The gelled foam exhibited good formation adaptability, profile control, and EOR performance. The foam flowed into the high permeability layer, plugged the dominant channel, and increased the swept volume. Oil recovery was enhanced by $29.4 \%$ under harsh high -temperature and high salinity conditions.
\end{abstract}

Keywords: gelled foam; conformance control; high temperature and high salinity; stabilization mechanism; enhanced oil recovery

\section{Introduction}

High temperature and high salinity reservoirs are widely distributed in oilfields in China. Most of these oilfields developed by water flooding, which led to the overdevelopment of the dominant channel following long-term water flooding [1-5]. Injected water can easily enter the production well along the dominant channels, which leads to a higher water cut and lower economic benefits of the production well. This high water cut in production wells has become a common problem in high temperature and high salinity oilfield developments [6-8]. Conformance control is widely used and has been proven to be an important measure to improve the efficiency of water flooding and enhance the oil recovery [9-14]. However, the lack of a suitable conformance control agent restricts the popularization and application of conformance control treatment in high temperature and high salinity reservoirs.

Many reservoirs suitable for conformance control are high temperature and high salinity reservoirs with temperatures reaching $100{ }^{\circ} \mathrm{C}$ and total dissolved-solids (TDS) of up to $22 \times 10^{4} \mathrm{mg} / \mathrm{L}$; most oil 
fields in northwest China fall into this category [15]. These conditions are extremely challenging for conformance control agents. Nevertheless, most traditional profile control agents do not meet the requirements of field applications. For example, polymer flooding is only suitable for low-temperature conditions of no higher than $90{ }^{\circ} \mathrm{C}$ since higher temperatures cause heat degradation in polymers [16]. Combined flooding, including alkaline-surfactant-polymer (ASP) flooding and surfactant-polymer (SP) flooding, is very difficult to apply under harsh conditions. It is limited by the stability of the alkalis and polymers under high temperature and high salinity conditions. However, foam has shown in the potential for conformance control in high temperature and high salinity reservoirs. Foam is a selective conformance control agent characterized by good chemical stability in high-temperature and salinity conditions [17-22]. Foaming agents have excellent performance as surfactants [23] and are chemical stable under harsh conditions [24]. Their good oil and water selectivity and the Jiamin effect make foam desirable for conformance control [25-27]. Foam increases the flow resistance of the injection water flowing in the dominant channels, promotes changes in flow direction, increases the swept volume, and results in enhanced oil recovery (EOR). Nevertheless, foam is an unstable system, which means that it will reduce the energy of the system by bubble destruction. What is worst, the harsh conditions of high temperature and high-salinity further aggravate the instability of foam systems [28,29]. Polymer is the most commonly used stabilizer to keep foam stable; however, it is only suitable for low-temperature conditions of no higher than $90^{\circ} \mathrm{C}$ because of heat degradation in polymers [30,31]. Nanoparticles are also very popular and effective stabilizers [32-35]. However, the poor dispersion ability of nanoparticles limits their application in high temperature and high salinity conditions. Gel has been used to keep foam stable in recent years. The combination of gel and foam (gelled foam) represents a potential agent for conformance control in high temperature and high salinity reservoirs. Gelled foam combines the good viscoelastic properties of a gel system with the excellent selective profile control of a foam system. The good viscoelastic properties of gel make foam more stable and stronger to allow control of the water injection in-depth profile. F.R. Wassmuth et al. [36,37] found that the gas-blocking ability of cured gel foam is far superior to that of polymer enhanced foam. K. Asghari [38], Wang X. [39] and F. Friedmann et al. [40] proved that the gel-foam is effective at blocking high permeability zones, improving oil recovery by water flooding in the low permeability zones. T.L. Hughes et al. [41] studied large volume foam gel treatments to improve conformance of $\mathrm{CO}_{2}$ flooding. The results from this study show that the foam-gel approach is with a cost-effective method to achieve in-depth conformance improvement in fractured reservoirs. However, all previous studies and applications have been conducted at low temperatures $\left(<90{ }^{\circ} \mathrm{C}\right)$ and salinities (5000 $\mathrm{mg} / \mathrm{L}$ ). There has been little study and application using gelled foam under the harsh reservoir conditions of high temperature and high salinity. What is more, a stable gelled foam that can withstand harsh conditions is very important to promote conformance control technology in northwest China.

In this study, we optimized a foaming agent and gel system under the harsh conditions of high temperature $\left(100^{\circ} \mathrm{C}\right)$ and high salinity $\left(22 \times 10^{4} \mathrm{mg} / \mathrm{L}\right)$. The gelled foam system was comprised of a foaming agent, gel system, and nitrogen. The foaming ability, microstructure, selective plugging performance, and EOR performance were also evaluated.

\section{Materials and Methods}

\subsection{Materials}

Magnesium chloride $\left(\mathrm{MgCl}_{2}\right)$, calcium chloride $\left(\mathrm{CaCl}_{2}\right)$, sodium chloride $(\mathrm{NaCl})$, and sodium dodecyl sulfate (SDS) were purchased from Sinopharm Co., Ltd. China and were analytically pure. Sulphobetaine (SB), sodium alkyl phenol polyoxyethylene ether carboxylate (APEC (Na)), partially hydrolyzed polyacrylamide (HPAM), and a phenolic cross-linker were purchased from Shandong Shida Oilfield Technical Services Co., Ltd. China. The average molecular weight of the HPAM was $3,800,000 \mathrm{~g} / \mathrm{mol}$ and the degree of hydrolysis was $5.59 \%$. Table 1 shows the composition of the 
simulated produced water. The core flooding experiment was conducted using sand packs and the bottle testing was conducted using high temperature ampoule bottles.

Table 1. Chemical analysis of the brine.

\begin{tabular}{cccccc}
\hline Ion Composition & $\mathbf{C a}^{2+}$ & $\mathbf{M g}^{2+}$ & $\mathbf{C l}^{-}$ & $\mathbf{N a}^{+}$ & Salinity \\
\hline Concentration $(\mathrm{mg} / \mathrm{L})$ & 9000 & 240 & 142,000 & 70,380 & 221,620 \\
\hline
\end{tabular}

\subsection{Measurements of Foaming Performance}

A foaming agent solution of $50 \mathrm{~mL}$, consisting of different mass fractions of the foaming agent, was poured into the foam performance evaluation device (Figure 1); the temperature was $100{ }^{\circ} \mathrm{C}$ and the pressure was $10 \mathrm{MPa}$ [42]. Subsequently, nitrogen was injected into the foam performance evaluation device through a gas inlet at the speed of 20 cubic centimeters per minute (CCM) for $5 \mathrm{~min}$. The foaming volume and volume half-life were recorded. The composite value was calculated with the following formula [43]:

$$
F=V_{0} \cdot t_{50}
$$

where, $F$ is the foam composite value in $\mathrm{mL} \cdot \mathrm{min}, V_{0}$ is the initial foam volume in $\mathrm{mL}$, and $t_{50}$ is the volume half-life (the time to reach half the volume of the initial foam volume) in min.

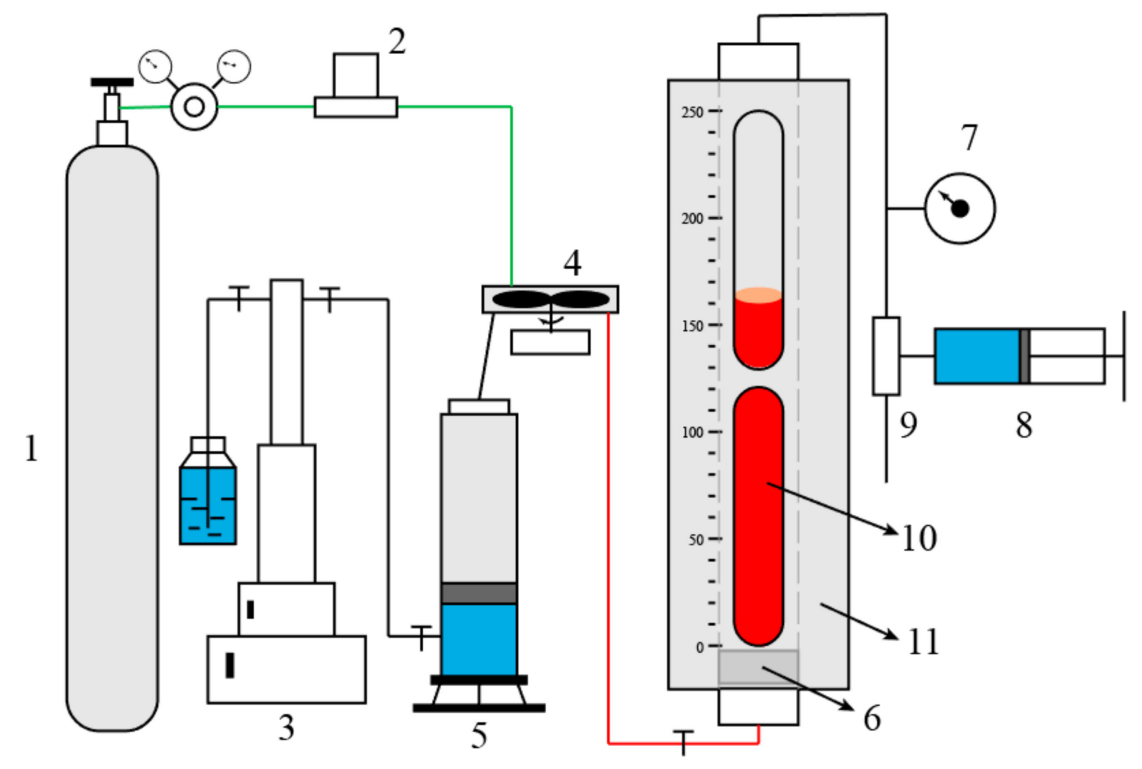

Figure 1. Foam performance evaluation device. 1-nitrogen; 2-mass flow gas meter; 3-constant-flux pump; 4-foam generator; 5-foaming agent; 6-porous media; 7-pressure meter; 8-hand pump; 9-back pressure valve; 10-foam; 11-heating jacket.

\subsection{Measurements of Interfacial Rheology}

Aqueous solutions $(0.2 \% w / w)$ were prepared for all the described foaming fractions and were analyzed with a dynamic interfacial oscillatory drop tensiometer (Teclis Tracker, Teclis Scientific, Tassin-la-Demi-Lune, Lyon, France). The purpose of the measurement is to form a bubble at the end of an inverted needle on the surface of the aqueous solution located in a transparent thermostatted cell. The bubble's profile was recorded in real time with a digital camera. The surface tension was calculated using Laplace's equation, which takes into account the capillary forces and gravity. The volume of a fresh bubble was $20 \mu \mathrm{L}$. The surface tension was monitored for fresh bubbles for $1 \mathrm{~h}$ at an oscillation frequency of $0.1 \mathrm{~Hz}$ and an amplitude of $1 \mu \mathrm{m}^{2}$ at $100{ }^{\circ} \mathrm{C}$. The validity of the measurements was 
checked by recording the standard error of the Laplacian drop at the beginning and at the end of each experiment.

\subsection{Measurements of Gelling Performance}

The gelant was prepared by adding cross-linker to the polymer solution. The polymer solution was prepared by adding the polymer to the brine at a certain mass fraction. Then, the gelant was injected into the ampoule bottle, which was then sealed. Finally, the ampoule bottle with the gelant was placed into an oven at a constant temperature of $100^{\circ} \mathrm{C}$. The gelling time was defined as the time when the gel strength reached $\mathrm{D}$ in the gel strength code [44].

\subsection{Measurements of Microstructure}

The microstructures of the gel samples with a gel strength code of D were analyzed using an environmental scanning electron microscope (ESEM), which allows for the observation of wet specimens in a low vacuum environment; this type of analysis maintains the structure of the gel. The gel specimens were prepared by removing a small sample from inside the gel. The specimens were analyzed in low vacuum mode at $15 \mathrm{kV}$ using the ESEM equipped with a back-scattered electron detector (BSED) and a Noran X-ray energy-dispersive spectrometry (XEDS) detector.

\subsection{Core Flooding Experiment}

Experimental setup: The schematic of the core flooding setup is shown in Figure 2. The setup consisted of one constant-flux pump, three intermediate containers, one sand pack (comprising two separate packs for the profile control performance and EOR experiment, as described in Table 2), and one precision pressure gauge. The sand packs and intermediate containers were placed in the oven at $100{ }^{\circ} \mathrm{C}$ to keep the core flooding system under reservoir conditions. The brine was injected into the sand packs by the pump at a constant flow rate. The foaming solution and nitrogen were mixed in the foam generator, and then the foam was injected into the sand pack. The pressure drop was recorded with a precision pressure gauge when the fluid flowed into the sand pack. Subsequently, the outflow of the sand pack was collected in a measuring cylinder.

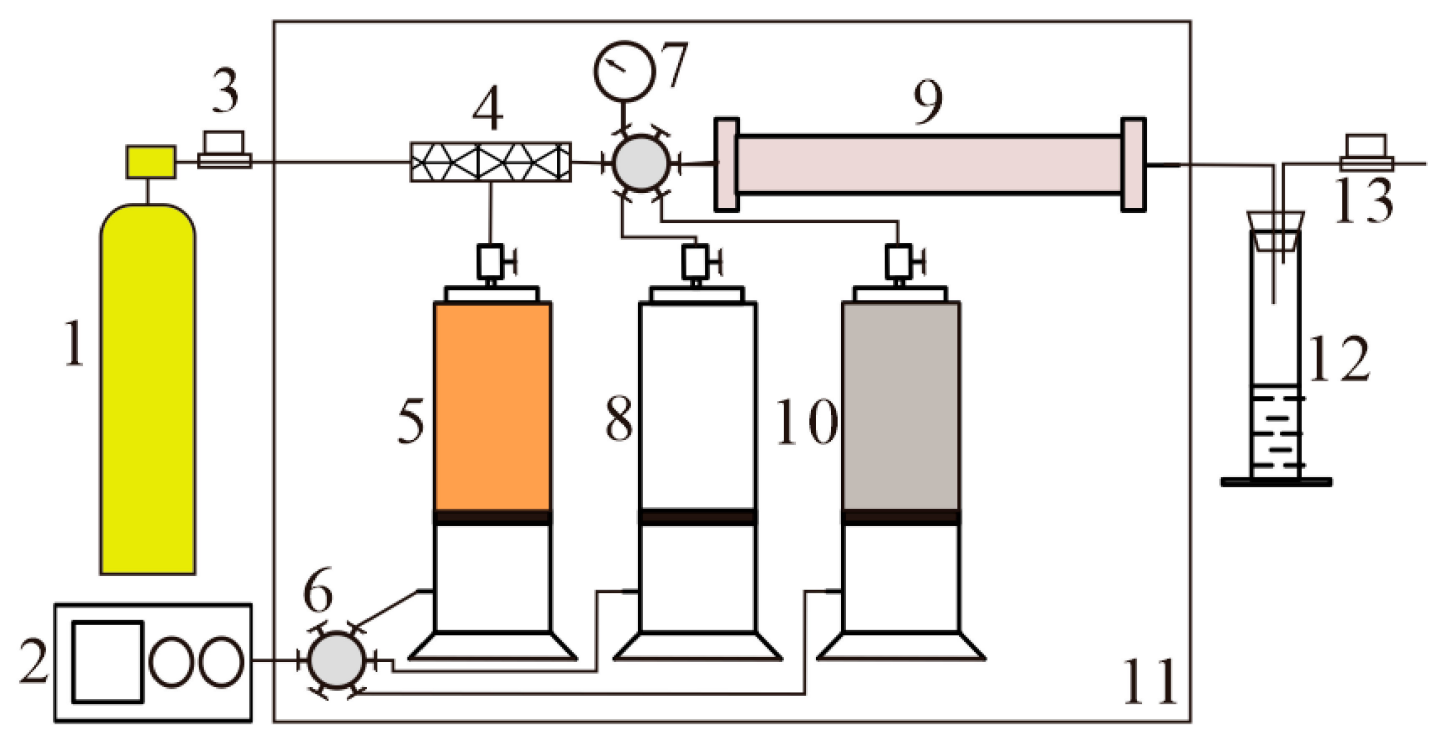

Figure 2. The experimental flow chart: 1-nitrogen; 2 -constant-flux pump; 3 -mass-flow gas meter; 4-foam generator; 5-gelling fluid; 6-valve; 7-pressure meter; 8-brine; 9-sand pack; 10 -crude oil; 11-oven; 12-burette; 13-gas flow meter. 
Table 2. Parameters of the sand pack physics model.

\begin{tabular}{|c|c|c|c|c|c|}
\hline \multicolumn{2}{|c|}{ Physics Model } & \multirow{2}{*}{$\begin{array}{c}\text { Length/cm } \\
20\end{array}$} & \multirow{2}{*}{$\frac{\text { Diameter/cm }}{2.5}$} & \multirow{2}{*}{$\begin{array}{c}\text { Permeability } / \mu \mathrm{m}^{2} \\
0.40\end{array}$} & \multirow{2}{*}{$\begin{array}{c}\text { Pore Volume/mL } \\
34\end{array}$} \\
\hline \multirow{4}{*}{ One sand pack } & No.1 & & & & \\
\hline & No. 2 & 20 & 2.5 & 1.10 & 35 \\
\hline & No.3 & 20 & 2.5 & 2.51 & 36 \\
\hline & No.4 & 20 & 2.5 & 5.66 & 37 \\
\hline \multirow{2}{*}{ Two sand packs } & High permeability & 20 & 2.5 & 2.53 & 36 \\
\hline & Low permeability & 20 & 2.5 & 0.48 & 34 \\
\hline
\end{tabular}

Resistance coefficient: The resistance coefficient [43] is a key parameter for measuring the injection performance of foam and is defined as follows:

$$
F_{R}=\frac{\lambda_{w}}{\lambda_{g}}
$$

where, $\lambda_{w}$ is the water mobility and $\lambda_{g}$ is the mobility of the gelant.

The foam fluid, consisting of the freshly foaming fluid and the nitrogen, was injected into the porous media ( $\varphi 25 \mathrm{~mm} \times 200 \mathrm{~mm}$ ) at a temperature of $100^{\circ} \mathrm{C}$. The injection pressure was recorded until the injected volume reached up to $1.0 \mathrm{PV}$, and the resistance coefficient was calculated.

Shutoff efficiency: The shutoff efficiency [45] is a key parameter for measuring the plugging capacity of foam and is defined as follows:

$$
E=\frac{k_{w 0}-k_{w 1}}{k_{w 0}}
$$

where, $k_{w 0}$ is the original permeability and $k_{w 1}$ is the permeability after the conformance control.

After injecting 1.0 PV of the foam fluid, the sand pack was maintained for three days at $100{ }^{\circ} \mathrm{C}$ to form the gelled foam. Then, the brine was injected into the sand pack at a rate of $1.0 \mathrm{~mL} / \mathrm{min}$, the injection pressure was recorded, and the shutoff efficiency was calculated.

\section{Results and Discussion}

\subsection{Optimization of the Gelled Foam}

\subsubsection{Optimization of Foaming Agent}

Foaming Performance

Different foaming agents with different concentrations were used to determine the foaming performance under the harsh conditions of $100{ }^{\circ} \mathrm{C}$ and $10 \mathrm{MPa}$. The results show (Figure 3) that the foam volume first increased and then stabilized as the concentration increased in the concentration range of $0.05-0.5 \%$. When the concentration of the foaming agent was lower than the critical micelle concentration $(\mathrm{CMC})$, the adsorption amount of the surfactant molecules at the gas-liquid interface increased as the concentration of the foaming agent increased. Meanwhile, the surface tension decreased, the free energy of the foam system decreased, and the foam system tended to stabilize. More bubbles were produced by forming more gas-liquid interfaces. After the concentration of the foaming agent reached the $\mathrm{CMC}$, the adsorption amount of the foaming agent at the gas-liquid interface no longer increased, while the surface tension lowered, and the surface energy of the system tended to remain unchanged. In addition, the foaming agent formed micelles, which increased the viscosity of the liquid phase so that the foaming volume no longer increased [46].

The volume half-life and foam composite value results were better for the SB than the other foaming agents. After the mass fraction of the foaming agent reached $0.2 \%$, the foaming performance 
of SB reached the maximum and was better than the performances of the other foaming agents. Therefore, for the subsequent experiments, SB was selected as the foaming agent for the gelled foam.
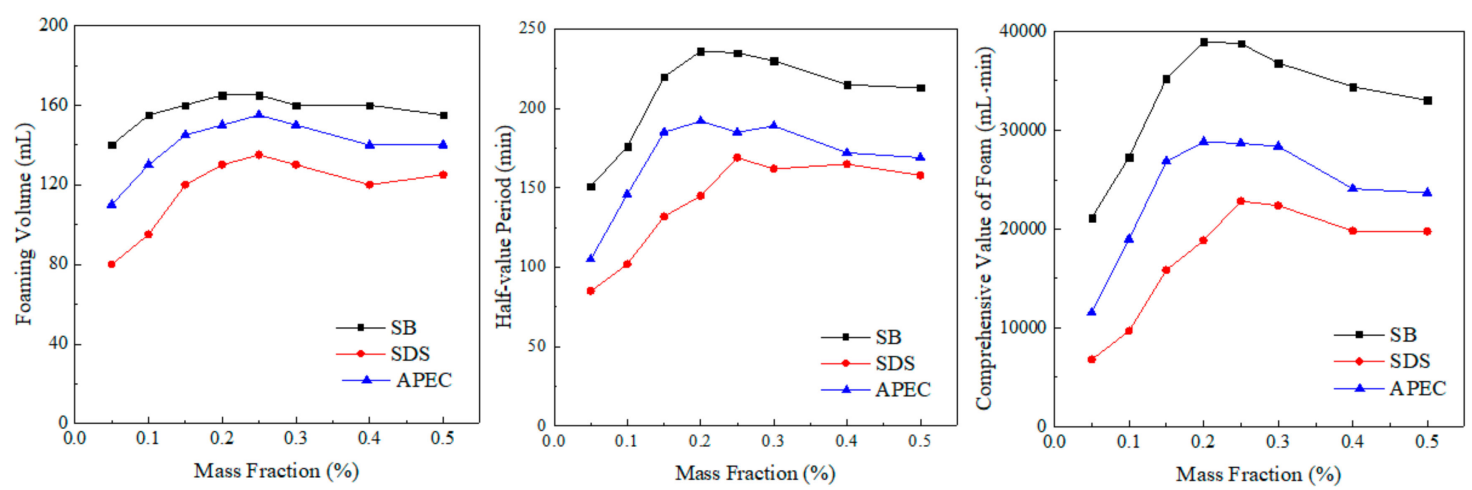

Figure 3. Foaming performance of different foaming agents.

Interfacial Rheology

The viscoelasticity of the foam interface plays an important role in the stability of the foam. The viscoelastic modulus of the interface prevents changes at the interface when the bubbles expand and shrink. It is defined as

$$
E=\frac{d \sigma}{\frac{d A}{A}}=\frac{d \sigma}{d \ln A},
$$

where, $E$ is the viscoelastic modulus, $\sigma$ is the interfacial tension, and $A$ is the surface area of the bubbles.

The viscoelastic modulus $(E)$ can be written in plural form in the experiment of the interface dilation modulus oscillation:

$$
E=E^{\prime}+i E^{\prime \prime},
$$

where, $E$ is the viscoelastic modulus, $E^{\prime}$ is the modulus of elasticity, and $E^{\prime \prime}$ is the viscosity modulus.

In order to determine the properties of the foaming agent at the microscopic level, the interfacial rheological property of the foam was evaluated. The results (Figure 4) show that the elastic modulus was significantly higher for SB than APEC and SDS. The higher viscosity modulus resulted in higher viscoelasticity and stronger mechanical strength of the membrane, leading to better self-repairing ability. Wang [47] investigated the relationship between the interfacial rheological properties and the foam stability using anionic surfactants. It was found that the greater the interfacial elastic modulus, the better the foam stability was. The elastic modulus of the foam film plays a key role in foam stability. An important property of an elastic foam film is the Marangoni effect [48]. When the foam film is subjected to disturbance or stress, it will become thinner. The surface tension of the foam film increases from $\sigma 1$ to $\sigma 2$, resulting in surface pressure in these areas. The molecules of the foaming agent and some water molecules will diffuse to the thinning surface as a result of the surface pressure and density difference. Subsequently, the film thickness and surface tension are restored to their original levels. 


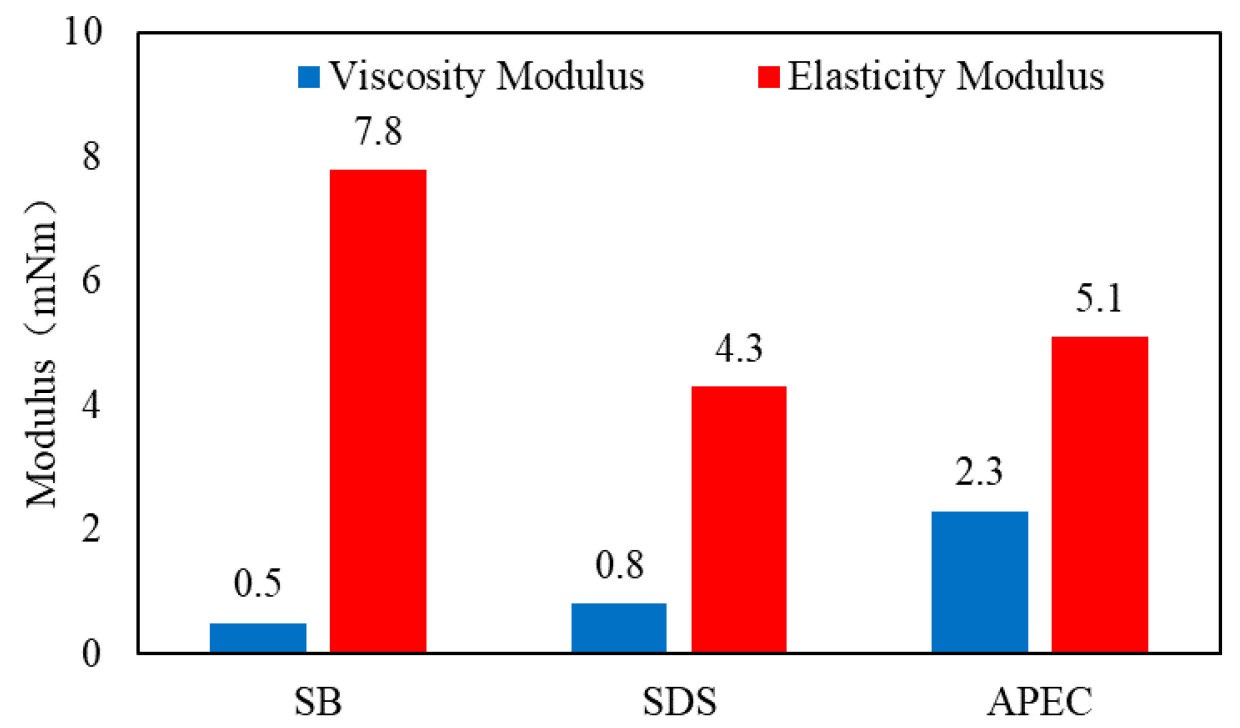

Figure 4. Viscoelastic modulus of different foaming agents: Sodium Dodecyl Sulfate (SDS), Sulphobetaine (SB), Sodium Alkyl Phenol Polyoxyethylene Ether Carboxylate (APEC).

\subsubsection{Optimization of the Gel}

Because the foam consists of multiple interfaces and is an unstable system with large interface energy, there was a tendency towards bubble collapse and reduction in the energy and a suitable foam stabilizer had to be added. Low cross-linked gels, which possess good ability to resist high temperatures and high salinity, can effectively increase the viscoelasticity of the foam's liquid membrane and improve the foam's stability. Therefore, based on the formulation of the gel and preliminary studies [49], HPAM/phenolic gel with a gel strength code of D was selected to stabilize the foam system [50]. The optimization experiment was conducted under reservoir conditions.

The results (Figures 5 and 6 ) show that the gel system consisting of the HPAM polymer and the phenolic cross-linker exhibited a good crosslinking effect under reservoir conditions. The gelling time ranged from $34 \mathrm{~h}$ to $80 \mathrm{~h}$ and the gel strength was very stable. The lifetime of a gel can be evaluated by dehydrates. The dehydration amount of the gel system $(0.4 \%$ HPAM $+0.06 \%$ phenolic cross-linker, Table 3) was able to be controlled in the range of $0-3 \%$ after aging for 60 days under reservoir conditions. A stable gel with an appropriate strength increases the viscoelasticity of the gelled foam and the strength of the foam liquid film consequently, improving the stability of the foam. A variable strength gel stabilizer was created by using $0.4 \%$ HPAM and $0.06 \%$ phenolic cross-linker by considering the strength, field injection ability, stability, and cost of gelled foam.

Table 3. Dehydration amount (\%) in isograms of gels under reservoir conditions.

\begin{tabular}{|c|c|c|c|c|}
\hline \multicolumn{5}{|c|}{$0.4 \%$ HPAM + $0.06 \%$ Phenolic Cross-Linker $\left(100^{\circ} \mathrm{C}\right)$} \\
\hline Aging Time (days) & 5 & 10 & 30 & 60 \\
\hline Dehydration amount (\%) & 0 & 1.2 & 1.5 & 1.5 \\
\hline
\end{tabular}




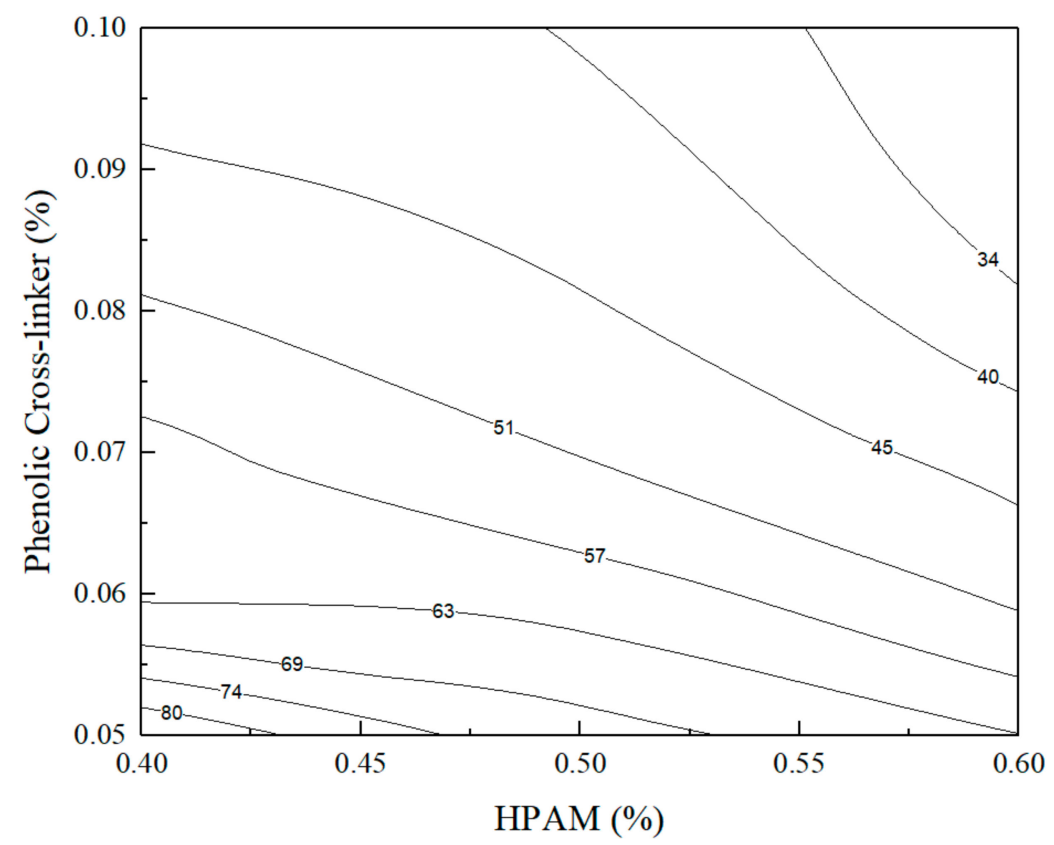

Figure 5. Gelling time of the gel consisting of a polymer (hydrolyzed polyacrylamide; HPAM) and a phenolic cross-linker $\left(100^{\circ} \mathrm{C}\right)$.
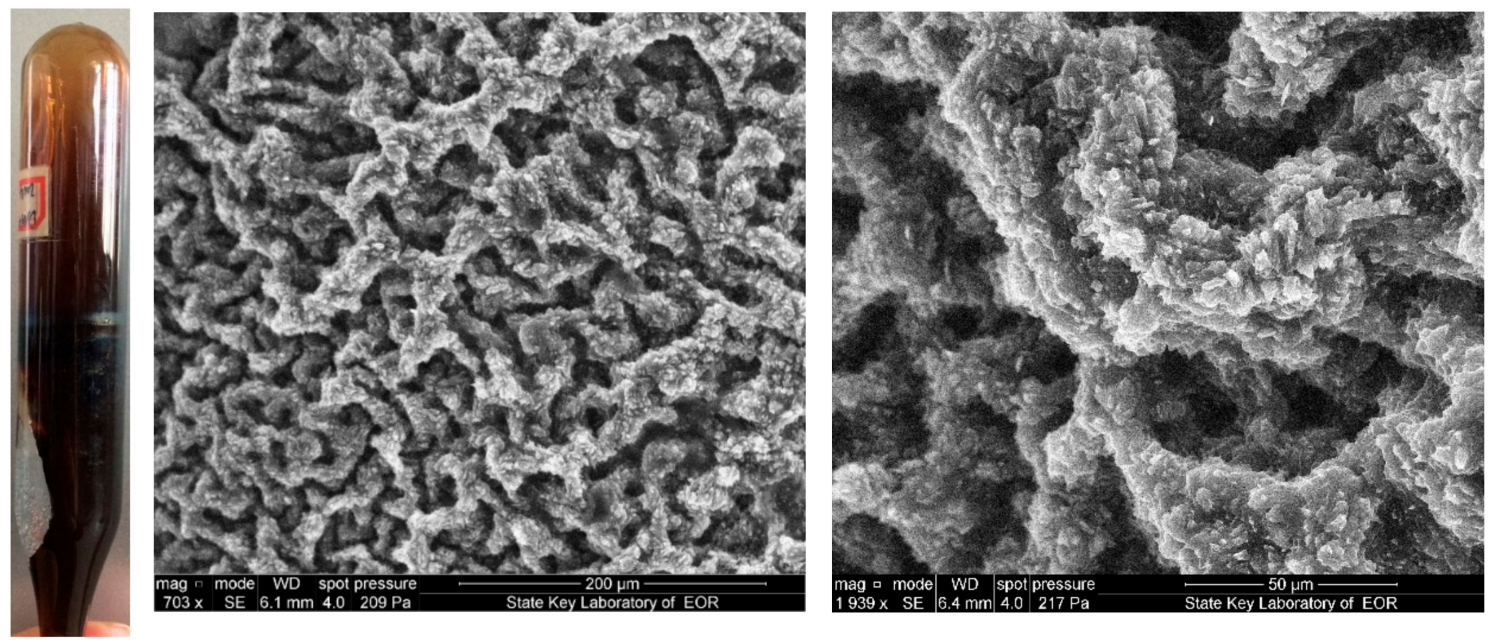

Figure 6. Microstructure of the gel with a gel strength code of D.

\subsubsection{Characterization of Gelled Foam}

\section{Foaming Performance}

The foam stability of the gelled foam system was higher than that of traditional foam (Figure 7). The volume half-life of the gelled foam system was 4.8 times that of traditional foam and the foam composite value was 3.8 times that of traditional foam. Although the foaming property of the gelled foam system was slightly lower due to the increase in viscosity, the foam stability and foam composite values were greatly improved. Therefore, the foaming property of the gelled foam system is superior to that of ordinary foam. 


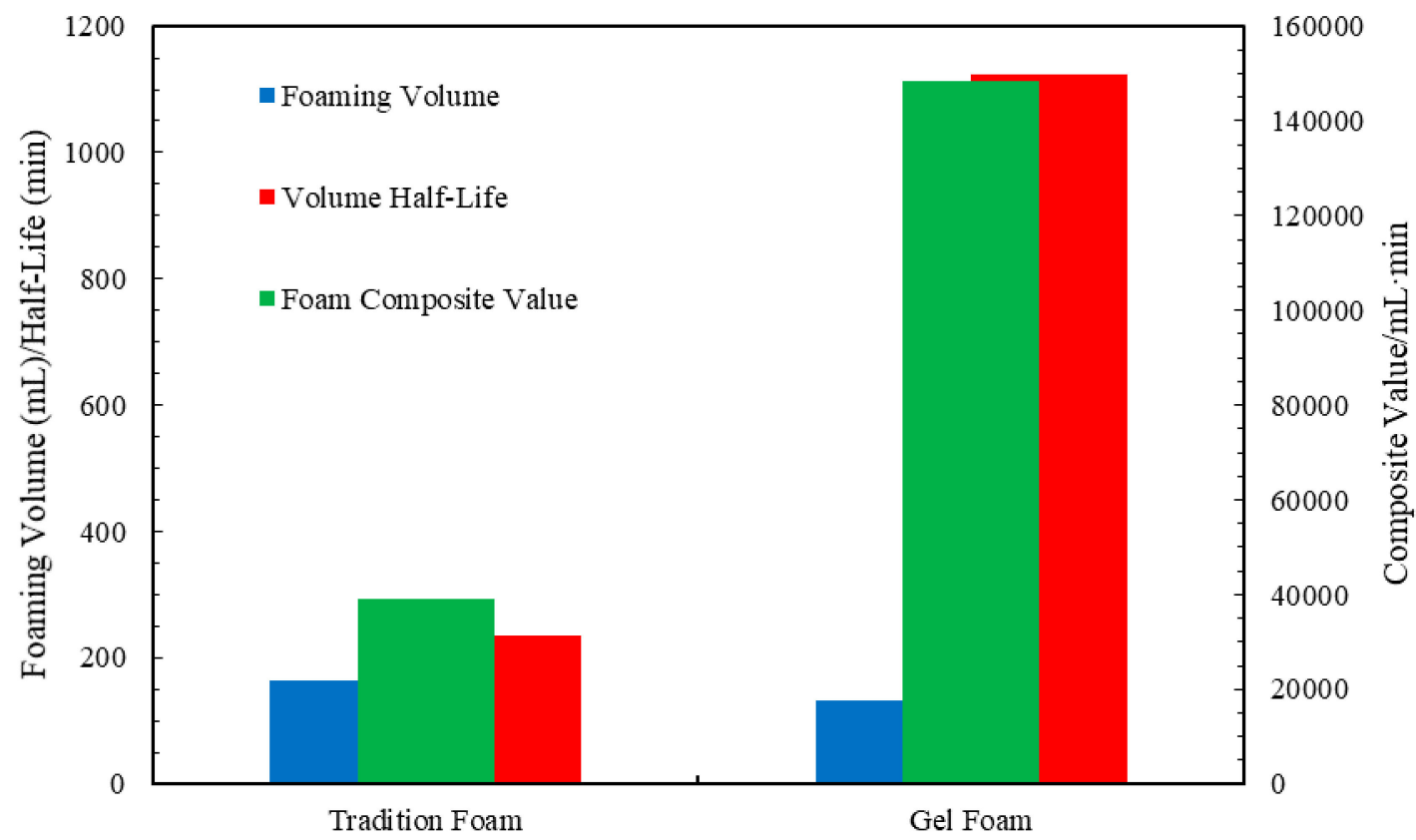

Figure 7. Effects of different gel formulas on the foam's properties.

\section{Foam Microstructure}

In order to observe the differences in the liquid membrane between the gelled foam and traditional foam, their microstructures were observed using an optical microscope. The foam system was prepared by stirring the foaming solution for $1 \mathrm{~min}$ at a speed of $1000 \mathrm{r} / \mathrm{min}$ at room temperature using a Warning blender. The microscopic images of the gelled foam and traditional foam (Figure 8) show that the gelled foam has a thicker foam film, which effectively suppresses the extrusion deformation of the bubbles, maintains an ideal thickness in the liquid film, and reduces the Plateau boundary effect and the diffusion of gases. These results demonstrate the stability of the gelled foam and improve the stability of the colloidal foam.

\section{Foam Stabilization Mechanism}

The breakup of foam is mainly caused by drainage and the air permeability of the foam film. It is common to improve the stability of foam systems with an increase in the liquid viscosity, in which polymers are the most commonly used stabilizers. However, most water-soluble polymers cannot resist high temperatures and high salinity conditions. Gel systems have several advantages over polymers. They not only resist these harsh conditions but also have better viscoelasticity than polymers. In order to gain a better understanding of the stabilization mechanism of gelled foam, a possible stabilization model was proposed. When the gel with the gel strength code of $\mathrm{D}$ was added to the foaming solution (Figure 9), it generated a stable three-dimensional network consisting of a liquid film. The particular structure of the liquid film provided a good skeleton for the adsorption of the foaming agent at the gas-liquid interface. Some polar groups of the foaming agent combined with the bound water in gel system were similar to a nail stuck in the three-dimensional network of the gel. The other polar groups of the foaming agent were attracted to the polar groups in the gel structure due to the intermolecular forces, resulting in stable adsorption and orderly arrangement of the molecules of the foaming agent at the gas-liquid interface. Moreover, the non-polar groups of the gel structure extended into the gas phase of the foam system and participated in the composition of the gas-liquid interface film, which greatly improved the stability of the composite interface film. In addition, the three-dimensional network of the liquid film increased the viscosity of the base liquid, reduced the drainage speed, and allowed for good self-repair ability under high temperatures and high salinity conditions. A thick 
and protective gel layer was observed around the bubbles in the gelled foam (Figure 8). The protective layer increased the viscoelasticity and weakened the permeability of the liquid film thereby improving the strength and thickness of the liquid film and maintaining the stability of the gelled foam.
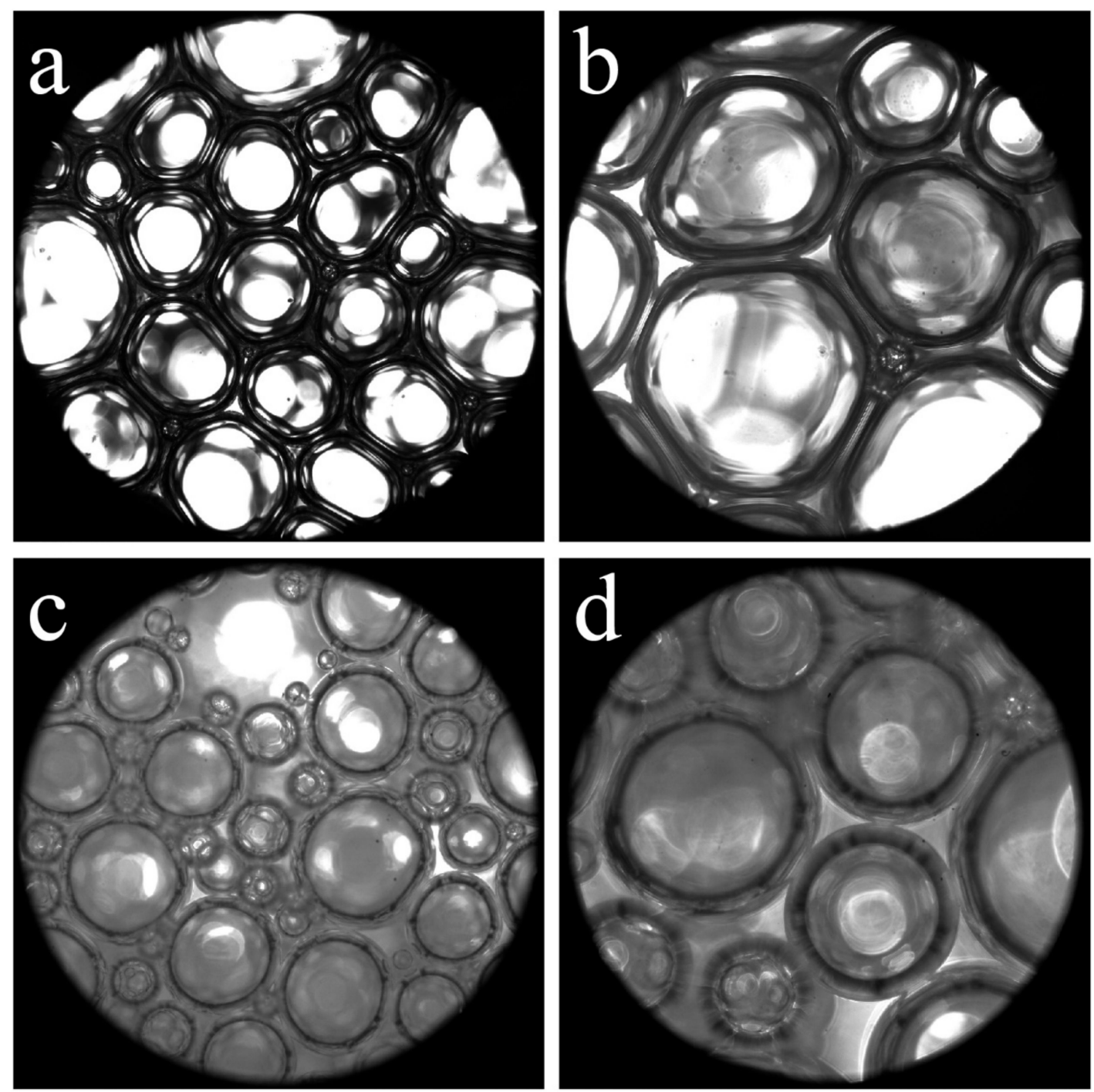

Figure 8. Microstructures of the gelled foam and traditional foam: (a) traditional foam (10×); (b) traditional foam $(20 \times)$; (c) gelled foam $(10 \times)$; (d) gelled foam $(20 \times))$.

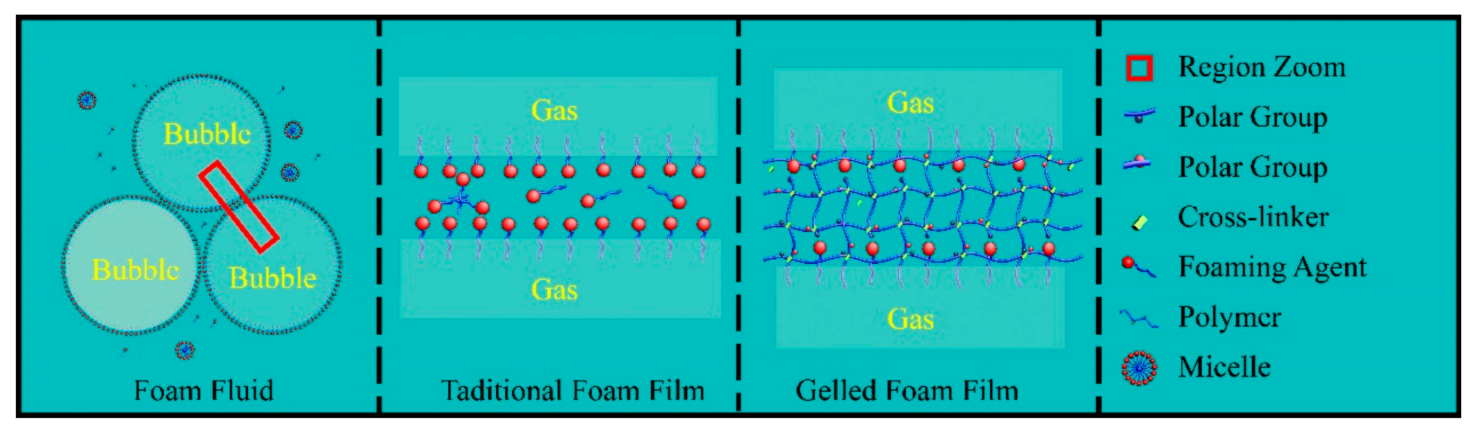

Figure 9. Stabilization mechanism of the gelled foam. 


\subsection{Formation Adaptability}

The formation permeability affects the profile control performance of gelled foam. This was evaluated by the resistance coefficient and the shutoff efficiency of the gelled foam. The gelled foam consisted of $0.4 \%$ polymer (HPAM), $0.06 \%$ cross-linker (phenolic) and $0.2 \%$ foaming agent (SB). The experimental parameters of the formation adaptability included a gas-liquid ratio of 1:1, a gas injection rate of $1.0 \mathrm{~mL} / \mathrm{min}$, and an injection volume of $1.0 \mathrm{PV}$. The results (Figure 10) showed that the resistance coefficient increases with the injection volume of the gelled foam. The resistance coefficient curves for the different permeabilities showed similar trends. The higher the permeability of the formation, the easier injection of the gelled foam was. The ease of injection ensured that the gelled foam enters the high permeability layer. However, the shutoff efficiencies were largely different for the different permeabilities. The shutoff efficiency increased as the permeability increased. This indicates that the gelled foam possesses good permeability and selective ability. The greater the permeability is, the higher the shutoff efficiency is, with a better performance of the profile control. Gelled foam has good plugging performance for high permeability formations and poor plugging performance for low permeability formations. This is mainly due to the strong shearing effect of the low permeability formations on the gelled foam, which has a negative impact on the stability of the gelled foam. The selective plugging ability of gelled foam allows it to flow into the dominant channels during the injection process; this plugs the dominant channel but not the low permeability layer. Thus, it effectively increases the swept volume of the driving water and improves the oil recovery.

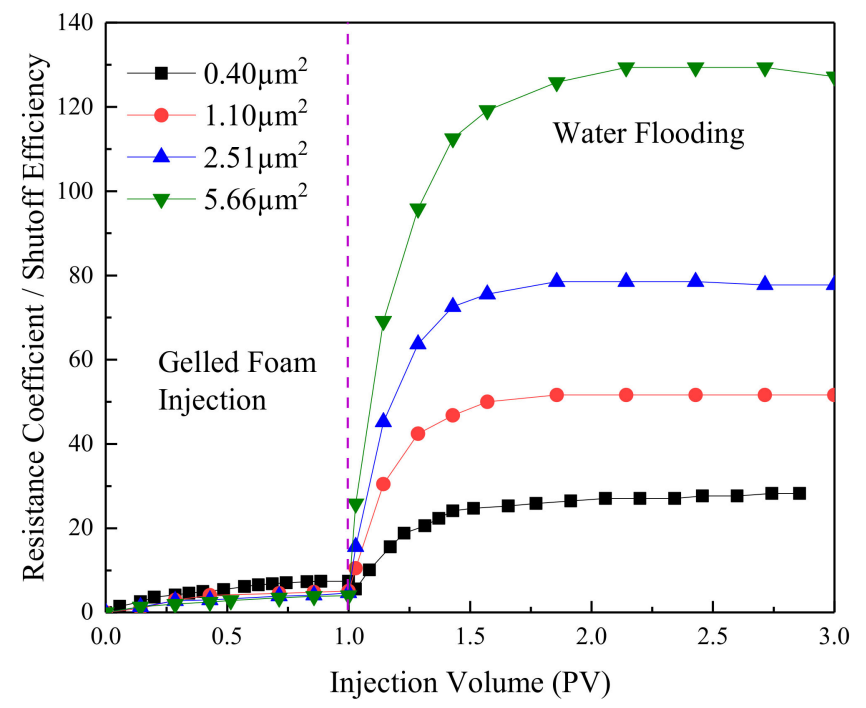

Figure 10. Effect of different permeabilities on the properties of the gelled foam.

\subsection{Profile Control Performance}

The profile control performance of the gelled foam was investigated under high temperature and high salinity conditions using a double sand pack physical model. The double sand pack physical model consists of two sand packs with different permeabilities, the sand pack with high permeability simulates a high permeability layer, and the sand pack with low permeability simulates a low permeability layer. The experimental results (Figure 11) show that the pressure of water flooding remained low and there was low volatility. Most of the liquid outflow originated from the high permeability layer and only about $4 \%$ of the liquid originated from the low permeability layer. Subsequently, $16 \mathrm{~mL}$ of the gelled foam was injected into the double sand pack physical model, and $12 \mathrm{~mL}$ of the gelled foam was injected into the high permeability layer. The results show that the gelled foam has good ability to selectively enter the high permeability layer. After aging for 3 days, the water flooding was tested again. However, the injection water was successfully diverted. 
The injection pressure was higher than prior to the injection of the gelled foam, and most of the liquid $(90 \%)$ outflow originated from the low permeability layer. This indicates not only that the gelled foam effectively controlled the water injection profile, but also that it increased the swept volume. Therefore, this demonstrates that the gelled foam has great potential for use as a conformance control in EOR.

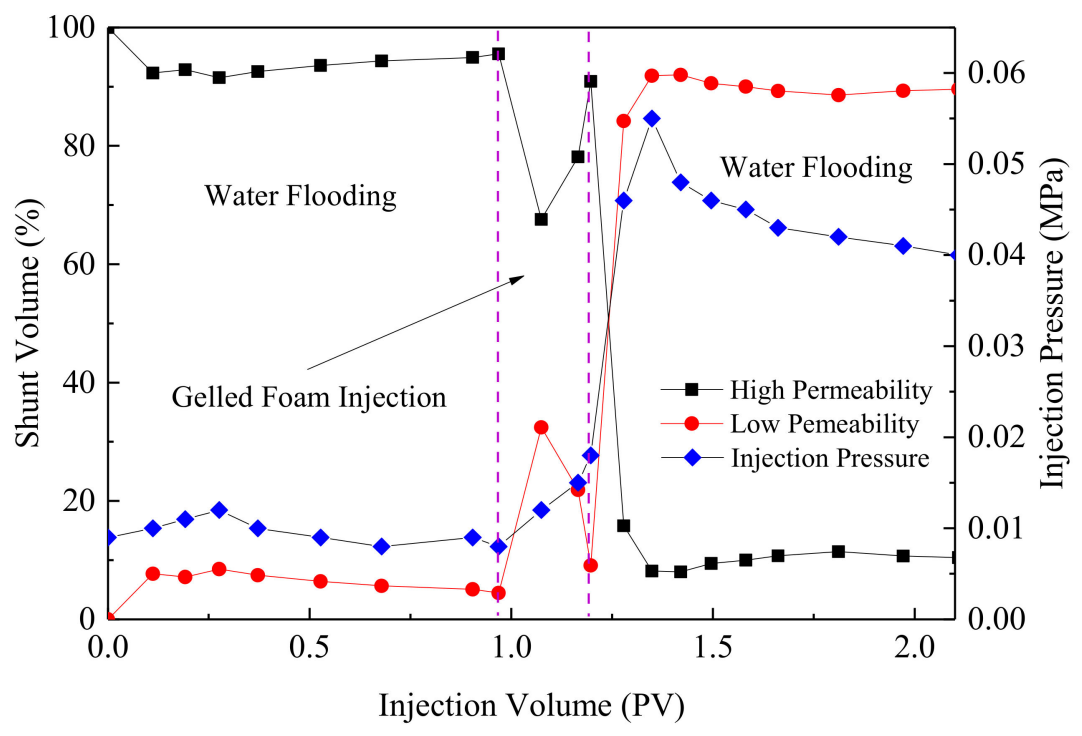

Figure 11. Injection pressure and outflow rate in the gelled foam profile control experiment.

\subsection{EOR Performance}

The EOR experiment was carried out under high temperature and high salinity conditions. The experimental parameters were the same as in the profile control experiment. The results (Figure 12) show the effect of conformance control. The oil recovery increased significantly by decreasing the water cut [51,52]. The conformance control increased the oil recovery by $29.4 \%$ based on the water flooding recovery of $32.2 \%$. The gelled foam preferentially flowed into the high permeability sand pack, plugging the high permeability layer effectively. Then, the injected water was forced to flow into the low permeability layer. The conformance of formation was controlled effectively, the swept volume of injected water was increased, and the remaining oil was displaced. The oil recovery was enhanced greatly.

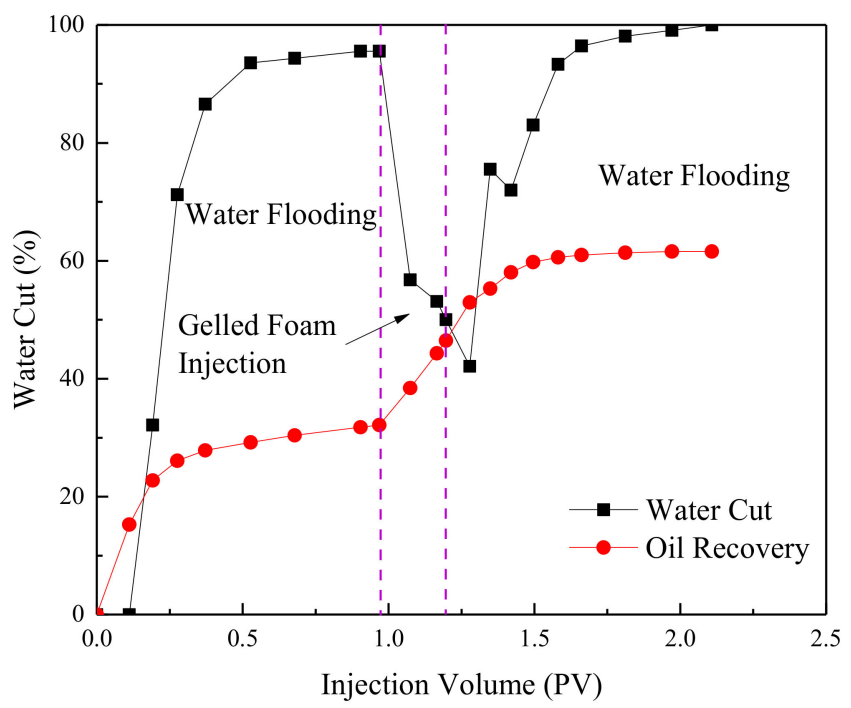

Figure 12. Enhanced oil recovery properties of the gelled foam system. 


\section{Conclusions}

In this study, a novel gelled foam was investigated in depth. The influences of the gel on foaming performance, including the volume, volume half-life, and the composite value of the foam, were investigated. The stabilizing mechanism of the gelled foam was investigated by determining the microstructure of the gel and foam. Core flooding experiments were also conducted. The major conclusions are summarized as follows:

(1) The gelled foam formulation is optimized with $0.4 \%$ polymer (HPAM), $0.06 \%$ cross-linker (phenolic) and $0.2 \%$ foaming agent (SB) under high temperature and high salinity conditions (temperature $100{ }^{\circ} \mathrm{C}$, TDS $22 \times 10^{4} \mathrm{mg} / \mathrm{L}$ ). The addition of the gel greatly improves the stability of the foam system, and the stability of the gelled foam is 3.8 times than that of a traditional foam.

(2) The SB foaming agent has a better elastic modulus, stronger self-repair ability, and better foam stability under high -temperature and high salinity conditions than other foaming agents. The addition of the gel results in a thick protective layer in the foam system that maintains the stability of the foam and improves the strength and thickness of the liquid film.

(3) The gelled foam has good formation adaptability, profile control, and EOR performance. It selectively flows into the high permeability layer, plugs the dominant channel, and increases the swept volume. The EOR was $29.4 \%$ under harsh high temperature and high salinity conditions.

(4) Higher temperature and salinity will definitely be a great challenge for future oil and gas development. Gelled foam is a kind of conformance control agent with great potential. Future challenges are the formation of high temperature and high-salinity reservoirs with temperatures reaching $140^{\circ} \mathrm{C}$ and total dissolved-solids (TDS) of up to $22 \times 10^{4} \mathrm{mg} / \mathrm{L}$.

Author Contributions: Q.Y. conceived the project and wrote the manuscript. T.L. and J.F. performed all the experiments and revised the manuscript. B.J. help with optimization of foaming agent. L.H. analysed the results of core flooding experiments. C.D. provide guidance in optimization of the gelled foam.

Acknowledgments: This work was supported by the National Science Fund (51504222 and U1663206), National Science and Technology Major Project (2016ZX05014005-008), the Climb Taishan Scholar Program in Shandong Province (tspd20161004), and the Graduate Innovation Project (YCX2017025). The authors express their appreciation to the technical reviewers for their constructive comments.

Conflicts of Interest: The authors declare no conflict of interest.

\section{References}

1. Coll, C.; Muggeridge, A.H.; Jing, X. Regional upscaling: A new method to upscale waterflooding in heterogeneous reservoirs for a range of capillary and gravity effects. SPE J. 2001, 6, 299-310. [CrossRef]

2. Loahardjo, N.; Xie, X.; Morrow, N.R. Oil recovery by sequential waterflooding of mixed-wet sandstone and limestone. Energy Fuels 2010, 24, 5073-5080. [CrossRef]

3. Xiao, B.; Zhang, X.; Wang, W.; Long, G.; Chen, H.; Kang, H.; Ren, W. A Fractal model for water flow through unsaturaturated porous rocks. Fractals 2018, 26, 1840015. [CrossRef]

4. Long, G.; $\mathrm{Xu}, \mathrm{G}$. The effects of perforation erosion on practical hydraulic-fracturing applications. SPE J. 2017, 22, 645-659. [CrossRef]

5. Brouwer, D.R.; Jansen, J.D. Dynamic optimization of waterflooding with smart wells using optimal control theory. SPE J. 2004, 9, 391-402. [CrossRef]

6. Han, D. An approach to deep development of high water-cut oil fields to improve oil recovery. Petrol. Exp. Dev. 1995, 22, 47-55.

7. Chunming, X.; Xiaofen, T. Technologies of water shut-off and profile control: An overview. Petrol. Exp. Dev. 2007, 34, 83-88.

8. Zongying, Z.; Kang, Z. Development situation and prospect of oil fields in China. Petrol. Exp. Dev. 2004, 31, 84-87.

9. You, Q.; Yu, H.; Wang, Y.; Zhang, J.; Yang, G.; Zhao, W.; Zhao, F. Technologies of in-depth profile control in China. Fault-Block Oil Gas Field 2009, 16, 68-71. 
10. Yao, C.; Lei, G.; Lei, L.; Gao, X. Selectivity of pore-scale elastic microspheres as a novel profile control and oil displacement agent. Energy Fuels 2012, 26, 5092-5101. [CrossRef]

11. Yao, C.; Lei, G.; Hou, J.; Xu, X.; Wang, D.; Steenhuis, T.S. Enhanced oil recovery using micron-size polyacrylamide elastic microspheres: Underlying mechanisms and displacement experiments. Ind. Eng. Chem. Res. 2015, 54, 1520-5045. [CrossRef]

12. Bai, B. Preformed particle gel for conformance control: Factors affecting its properties and applications. SPE Reserv. Eval. Eng. 2007, 10, 415-422. [CrossRef]

13. Bai, B.; Zhou, J.; Yin, M. A comprehensive review of polyacrylamide polymer gels for conformance control. Petrol. Exp. Dev. 2015, 42, 525-532. [CrossRef]

14. Bai, B.; Huang, F.; Liu, Y.; Seright, R.S.; Wang, Y. Case study on prefromed particle gel for in-depth fluid diversion. In Proceedings of the SPE Symposium on Improved Oil Recovery, Tulsa, OK, USA, 20-23 April 2008.

15. Jichao, F.; Jianhai, W.; Quanyi, W.; Sisi, F.; Xiaoqing, H.; Yan, M. Research of phenolic crosslinker gel for profile control and oil displacement in high temperature and high salinity reservoirs. J. Appl. Polym. Sci. 2018, 135, 46075.

16. Jia, H.; Pu, W.F.; Zhao, J.Z.; Liao, R. Experimental investigation of the novel phenol-formaldehyde cross-linking hpam gel system: Based on the secondary cross-linking method of organic cross-linkers and its gelation performance study after flowing through porous media. Energy Fuels 2011, 25, 727-736. [CrossRef]

17. Puerto, M.; Hirasaki, G.J.; Miller, C.A.; Barnes, J.R. Surfactant systems for EOR in high-temperature, high-salinity environments. SPE J. 2010, 17, 11-19. [CrossRef]

18. Xiao, B.; Wang, W.; Fan, J.; Chen, H.; Zhao, D.; Zhang, X.; Ren, W. Optimization of the fractal-like architecture of porous fibrous materials related to permeability, diffusivity and thermal conductivity. Fractals 2017, 25, 1750030. [CrossRef]

19. Kovscek, A.R.; Bertin, H.J. Foam mobility in heterogeneous porous media. Transp. Porous Media 2003, 52, 17-35. [CrossRef]

20. Xiao, B.; Chen, H.; Xiao, S.; Cai, J. Research on relative permeability of nanofibers with capillary pressure effect by means of fractal-monte carlo technique. J. Nanosci. Nanotechnol. 2017, 17, 6811-6817. [CrossRef]

21. Li, R.F.; Yan, W.; Liu, S.; Hirasaki, G.; Miller, C. Foam mobility control for surfactant enhanced oil recovery. SPE J. 2010, 15, 928-942. [CrossRef]

22. Shan, D.; Rossen, W.R. Optimal Injection Strategies for Foam IOR. SPE J. 2004, 9, 75180. [CrossRef]

23. Dai, C.; Zhao, J.; Yan, L.; Zhao, M. Adsorption behavior of cocamidopropyl betaine under conditions of high temperature and high salinity. J. Appl. Polym. Sci. 2014, 131, 383-390. [CrossRef]

24. Ji, Z.; Jichao, F.; Daiyu, Z.; Jianhui, Z.; Shiti, C.; Caili, D. Surfactant Flooding in Tazhong 402 CIII High-Temperature and High-Salinity Reservoir. Oilfield Chem. 2014, 31, 405-409.

25. Jichao, F.; Caili, D.; Qing, Y. Study on foam flooding in high-temperature and high-salinity reservoir of Tazhong 402CIII. Petrol. Geol. Recovery Effic. 2014, 21, 84-88.

26. Zhao, F. Principle of EOR; China University of Petroleum Press: Dongying, China, 2016; Chapter 6; p. 118.

27. Wang, P. Overview on technology of water shut off/profile control agent of foam. Drill. Prod. Technol. 2000, 23, 60-61.

28. Zhao, G.; Dai, C.; Zhang, Y.; Chen, A.; Yan, Z.; Zhao, M. Enhanced foam stability by adding comb polymer gel for in-depth profile control in high temperature reservoirs. Colloids Surf. A Physicochem. Eng. Asp. 2015, 482, 115-124. [CrossRef]

29. Dai, C.; Feng, H.; Jian, J.; Zhao, M.; He, X.; Zhao, J. A selective water-plugging system with heat-resistant gelled foam: A case study from the East China sea gas field. Nat. Gas Ind. 2015, 35, 60-67.

30. Huh, C.; Rossen, W.R. Approximate pore-level modeling for apparent viscosity of polymer-enhanced foam in porous media. SPE J. 2008, 13, 17-25. [CrossRef]

31. Telmadarreie, A.; Trivedi, J.J. New insight on carbonate heavy oil recovery: Pore scale mechanisms of solvent alternating $\mathrm{CO}_{2}$ foam/polymer enhanced foam flooding. In Proceedings of the SPE Canada Heavy Oil Technical Conference, Calgary, AB, Canada, 9-11 June 2015.

32. Nguyen, P.; Fadaei, H.; Sinton, D. Pore-scale assessment of nanoparticle-stabilized $\mathrm{CO}_{2}$ foam for enhanced oil recovery. Energy Fuels 2014, 28, 6221-6227. [CrossRef]

33. Guo, F.; Aryana, S. An experimental investigation of nanoparticle-stabilized co2 foam used in enhanced oil recovery. Fuel 2016, 186, 430-442. [CrossRef] 
34. San, J.; Wang, S.; Yu, J.; Liu, N.; Lee, R. Nanoparticle-stabilized carbon dioxide foam used in enhanced oil recovery: Effect of different ions and temperatures. SPE J. 2017, 22, 179628. [CrossRef]

35. Rognmo, A.U.; Heldal, S.; Fernø, M.A. Silica nanoparticles to stabilize $\mathrm{CO}_{2}$-foam for improved $\mathrm{CO}_{2}$ utilization: Enhanced $\mathrm{CO}_{2}$ storage and oil recovery from mature oil reservoirs. Fuel 2018, 216, 621-626. [CrossRef]

36. Wassmuth, F.R.; Hodgins, L.H.; Schramm, L.L.; Kutay, S.M. Screening and coreflood testing of gel foams to control excessive gas production in oil wells. In Proceedings of the SPE/DOE Improved Oil Recovery Symposium, Tulsa, OK, USA, 3-5 April 2000.

37. Wassmuth, F.R.; Hodgins, L.A.; Schramm, L.L.; Kutay, S.M. Screening and coreflood testing of gel foams to control excessive gas production in oil wells. SPE Reserv. Eval. Eng. 2001, 4, 72096. [CrossRef]

38. Asghari, K.; Taabbodi, L.; Dong, M. A new gel-foam system for water shut-off purposes in wormhole reservoirs. In Proceedings of the SPE International Thermal Operations and Heavy Oil Symposium, Calgary, AB, Canada, 1-3 November 2005.

39. Wang, X.; Dong, M.; Zhou, W. Polymer/gel enhanced foam flood for improving post-waterflood heavy oil recovery. In Proceedings of the SPE Heavy Oil Conference-Canada, Calgary, AB, Canada, 11-13 June 2013.

40. Friedmann, F.; Hughes, T.L.; Smith, M.E.; Hild, G.P.; Wilson, A.; Davies, S.N. Development and testing of a foam-gel technology to improve conformance of the Rangely $\mathrm{CO}_{2}$ flood. SPE Reserv. Eval. Eng. 1999, 2, 54429. [CrossRef]

41. Hughes, T.L.; Friedmann, F.; Johnson, D.; Hild, G.P.; Wilson, A.; Davies, S.N. Large-volume foam-gel treatments to improve conformance of the Rangely $\mathrm{CO}_{2}$ Flood. SPE Reserv. Eval. Eng. 1999, 2, 54772. [CrossRef]

42. Zhang, Y.; Dai, C.; Xu, X.; Wang, S.; Yan, L.; Xin, C. Research and application on nitrogen foam flooding in Henan Oilfield. Fault-Block Oil Gas Field 2013, 20, 129-132.

43. Li, B. Study on Profile Control and Flooding Technology of Nitrogen Foam and Its Applicability; China University of Petroleum Press: Dongying, China, 2007.

44. Sydansk, R.D. Delayed In-situ Crosslinking of Acrylamide Polymer for Oil Recovery Application in High Temperature Formation. U.S. Patent 4,844,168, 4 July 1989.

45. Zhao, F.L. Oilfield Chemistry; China Petroleum University Press: Dongying, China, 2001; pp. $95-96$.

46. Guo, Z.; Xu, C.; Lu, Y. Foamability and stability of foam and means of evaluating. Chem. Eng. 2006, 4, 51-54.

47. Wang, L.; Yu, T.; Cao, Q.; Cao, Y.; Meng, Q. Interfacial Viscoelasticity and Performance Properties of BS-12 Foam for EOR. Oilfield Chem. 2007, 24, 70-74.

48. Xie, J.; Fan, S. On Foam Stability. Oildfield Chem. 1988, 5, 56-63.

49. Fang, J.; Zhang, X.; He, L.; Zhao, G.; Dai, C. Experimental research of hydroquinone (HQ)/hexamethylene tetramine (HMTA) gel for water plugging treatments in high-temperature and high-salinity reservoirs. J. Appl. Polym. Sci. 2017, 134, 44359. [CrossRef]

50. Wang, J.; Wang, S.; Zhao, S. Study on profile control and oil displacement system for gelled foam of high-temperature reservoir in Zhao'ao oilfield. Petrol. Geol. Recovery Effic. 2013, 20, 57-61.

51. You, Q.; Wang, H.; Zhang, Y.; Liu, Y.; Fang, J.; Dai, C. Experimental study on spontaneous imbibition of recycled fracturing flow-back fluid to enhance oil recovery in low permeability sandstone reservoirs. J. Petrol. Sci. Eng. 2018, 166, 375-380. [CrossRef]

52. Liu, S.; Wang, J.; He, H.; Wang, H. Mechanism on Imbibition of Fracturing Fluid in Nanopore. Nanosci. Nanotechnol. Lett. 2018, 10, 87-93. [CrossRef]

(C) 2018 by the authors. Licensee MDPI, Basel, Switzerland. This article is an open access article distributed under the terms and conditions of the Creative Commons Attribution (CC BY) license (http://creativecommons.org/licenses/by/4.0/). 